\title{
The perceptions of teachers and heads of department on the roles of a formal mentor in a Zambian Secondary School
}

Madalitso Khulupirika Banja

Department of Educational Psychology, Sociology and Special Education, University of Zambia, Zambia

Vol 1 No 12019

ISSN: 2788-6298

DOI: https://doi.org/10.35293/tetfle.v1i1.62

\section{ABSTRACT}

This paper reports on research work concerning the perceptions of newly qualified teachers (NQTs) and heads of department (HoDs) regarding the roles of formal mentors in helping newly qualified teachers in selected secondary schools in Zambia. These NQTs could be products of a conventional teacher preparation programme through fulltime study, part-time or parallel study, or an Open and Distance Learning Programme. The purpose of the study was to establish what NQTs and HoDs believed to be key areas in which NQTs needed to be mentored in order to help them adapt to the requirements of their teaching roles in schools. It uses quantitative data that were collected from the NQTs and HoDs using self-administered questionnaires guided by Kram's Mentor Role Theory. Data were collected from a sample of 191 participants that comprised 92 NQTs and 99 HoDs. Quantitative data were analysed using the Chi Square test. Quantitative results suggest that there was a huge discrepancy in the perceptions of NQTs and HoDs regarding the roles of a formal mentor in helping NQTs in their work. The paper proposes the development of a policy on mentorship of NQTs and a mentorship framework to ensure harmonization of understanding of mentorship and its effective implementation.

Keywords: Perceptions, newly qualified teachers, formal mentor, mentoring, school-based support, initial teacher education.

CONTACT Madalitso Khulupirika Banja @ chilusbanja@yahoo.com 


\section{Introduction}

This paper discusses the perceptions of NQTs (newly qualified teachers) and HoDs (Heads of Departments) on the roles of formal mentors in helping NQTs in their work. For the purposes of this discussion, a NQT is defined as a certified teacher who has worked post-qualification for a period ranging between 6-24 months. The notion of mentoring is a concept that has its roots in Greek mythology and is anchored on a more experienced adult offering help and guidance to a younger person (Ragins and Kram, 2007). Mentoring is defined by Bartell (2005:90) as:

Professional practice that occurs in the context of teaching whenever an experienced teacher supports, challenges and guides novice teachers in their teaching practice.

While definitions of mentoring remain fluid, my choice of definition is deliberately meant to galvanise interest in the mentor-mentee relationship. With specific reference to education, Lankau and Scandura, (2007: 95) have attributed the need for mentoring of NQTs to the limitations of tertiary level training, and propose school-based mentoring as a possible solution:

Learning from training programmes and books will not be sufficient to keep pace with required competencies for success in today's fast-paced work environments. Individuals often must look to others to learn new skills and keep up with the demands of their jobs and professions. Mentoring relationships can serve as a forum for such personal learning in organisations.

Interesting too, and corroborating with Lankau and Scandura (2007), Bolam (1984) when discussing the circumstances of NQTs in Britain, argues that no matter how good teacher courses were, they were intrinsically general and therefore peripheral to the NQT's major professional concerns which revolved around their particular pupils, classrooms and schools. As Powers (2012: 24) has stated 'new teachers generally do not have the content 
knowledge, instructional and management strategies, or ability to perform at the same level as experienced teachers.'

Newly qualified teachers' main source of practical help was in the school. One way of supporting new teachers towards success is through mentoring (Lortie, 2002). The first year in teaching is recognised as an important segment that has a tremendous impact on a teacher's professional career and personal life (Greiman, 2002), and it is believed to have long term implications for achieving effective teaching, job satisfaction, and career length.

From the literature on NQTs in Zambia, there is ample evidence that most teachers have not received mentorship because mentorship programmes for NQTs in Zambian schools were isolated and unsystematic (Malasha, 2009).

\section{Problem Statement}

A global review of literature on mentoring of NQTs points to the immeasurable value of mentorship in facilitating preparation for and smooth transition into the teaching profession. In addition, mentoring has been found to increase job satisfaction, reduce the stress level of NQTs and assist their professional growth (Galvez-Hjornevik, 1985).

In Zambia, very little is known about the practice of mentorship as a strategy for supporting NQTs and the potential it holds for their personal and professional growth. As Malasha (2009) found, mentorship programmes for NQTs in Zambian secondary schools were isolated and unco-ordinated. This is so inspite of widespread findings which suggest, as Greiman (2002) reports, that without mentorship, new teachers learn through time consuming and stressful trial and error and yet are given a wide range of responsibilities which they are expected to execute in the same manner as veteran teachers. Little (1990) found that mentoring has become the preferred method of dealing with teacher induction, and takes precedence over reduced workload, peer group support, and formally structured continuous professional development. The capacity to develop professional competence in NQTs early in their practice has profound implications for 
learner achievement. There is substantial evidence in the literature from Western and Asian countries in support of the benefits of mentorship of NQTs as an effective tool for ensuring quality teachers (Dougherty and Dreher, 2007). Despite mentoring of NQTs having been in academic discourse over many decades, there is no known study in Zambia about the perceptions of teachers and HoDs towards the roles of a formal mentor in helping newly qualified teachers. Against this background, this paper explored the perspectives of teachers and head teachers on the roles of formal mentors in helping newly qualified teachers.

Based on this lack of research and the need to understand what key stakeholders perceive to be the roles of a formal mentor in helping NQTs, the researcher phrased the research question: what are the perceptions of newly qualified teachers and heads of department of the roles of a formal mentor in helping newly qualified teachers in selected secondary schools in Zambia?

\section{Theoretical Framework}

This study was guided by Mentor Role Theory (Kram, 1985) which suggests that mentoring is a developmental relationship that enhances professional growth and advancement in an individual. However, Kram's' theory focuses solely on what CochranSmith and Paris (2005) cited in (Richter et al., 2013: 168), refer to as knowledge transmission:

According to the knowledge transmission model, mentors perceive their role as expert teachers and transmit their knowledge within a hierarchically structured relationship. In this learning environment, novices are socialised into the prevailing culture of schooling, which manifests the status quo.

Also known as conventional mentoring (Richter et al., 2013), Kram's model of mentorship focuses on 'situational adjustment to the new school environment, technical advice, and emotional support. As Richter et al. have argued, this approach to mentoring by Kram has a leaning towards behaviorist theories of learning 'which conceptualise learning as 
the accumulation of knowledge provided by experts. This mentoring style is what Richter et al. have labelled transmission-oriented mentoring.

By recognising the knowledge and experience of veteran teachers and in addressing the needs of NQTS, Kram's theory renders itself extremely suitable for this study as it helps the researcher explain amongst others, the nature of professional interaction between veteran teachers and novice teachers, the necessity for professional collegiality, the environment under which such professional collegiality should take place and most significantly, the expected outcomes, namely, equipping NQTs with appropriate knowledge and skills that they require to competently discharge their duties as classroom teachers.

\section{The role of the mentor}

The need for a mentor in the school system has been highlighted by numerous empirical studies across the world. Wildman, Niles, Maglario \& McLaughlin (1987) cited in (Bash and Turner, 1999) have alluded to how critical this support is during the first year of teaching when while learning how to teach, NQTs have to be in the classroom teaching. The mentor as a more experienced teacher is expected to provide professional guidance and support to the newly qualified teacher for a given duration. A review of literature conducted by Huling-Austin (1990) cited in Greiman et al., 2007) of teacher induction programmes reveals that the most consistent finding across studies is the importance of the mentor teacher. Several scholars (Verasai, 2016; Jyoti \& Sharma, 2015; Dougherty and Dreher, 2007; Powell, 1997; Kram, 1985) have advanced that mentors can help an individual's career advancement in an organisation.

Mentors not only provide content in the form of skills and valued behaviours, but also provide social related mentoring through offering emotional attachment through support and encouragement and providing networking opportunities to the mentee (Kram, 1985). Similarly, Powell (1997) says that the role of the psychosocial mentor aims at changing the social circumstances of the mentee, influencing the mentee personally and serving as a role model by way of encouraging, counselling and supporting the mentee. In 
agreeing with Powell (1997), Ismail-and Arokiasamy (2007) further state that mentoring provides support as a mentor acts as a role model. The role of the mentor is to pass on knowledge through teaching and coaching, experience and judgment, and/or to provide guidance and support so that he/she (the mentee) progresses in his/her career.

In particular, the mentor has the responsibility to provide guidance and assistance on lesson preparation, teaching methodology, integration of the NQTs into the school environment. The mentor is also a valuable aid pedagogically and socially. $\mathrm{He} / \mathrm{she}$ is a role model and provides moral and social direction to the NQT for him or her to discharge his/her duties satisfactorily. Similarly, other studies on mentorship have established that integral to mentoring are the related notions of the formation of trust, emotional attachment and confidence-building by the mentor Morton-Cooper and Palmer (2000) and Surtees (2008) cited in Lennox, Skinner and Foureur (2008). The goal of counselling in mentorship is to equip the novice to handle personal anxieties, fears and ambivalence effectively to the extent that they do not adversely affect their work. It is clear from the literature that the role of a mentor is critical in the career progression of a newly qualified teacher.

Mentors draw upon their own experiences as effective classroom instructors to quickly guide NQTs toward best practices that help them to discover what is working in their classrooms as well as identifying, facing and whenever possible resolving the challenges. A strong teacher mentoring programme also facilitates the sharing of information with the novice teachers about both the professional work of a teacher and the daily job of classroom teaching to assist them in being adequately prepared and engaged in the educational process (Clutterbuck, 2007; Renwick, 2007; Wayne, Youngs, \& Fleischman, 2005; Wong, 2004).

Another study of an existing mentoring programme by McCollum (2014) revealed that being assigned a mentor was greatly appreciated by beginning teachers who valued the emotional and physical support, and positive guidance that came with having a mentor. 
Similarly, Brading (1999) found that NQTs appreciated psychosocial support in their first year of teaching.

In transformation mentoring, also coined educative mentoring by Feiman-Nemser (2003) as cited by Richter (2013), mentors provide opportunities that foster growth and development. They interact with their novices in a way that supports inquiry and that enables them to learn in and from their practice.

\section{Methodology}

Perceptions may be determined by a variety of contextual circumstances which include but is not limited to age, sex, education level, and so on (Gwaa-Uugwanga, 2015). As McCollum (2014: 37) has further argued, 'to effectively support beginning teachers, it is important to listen to their voices and observe their experiences' hence the choice of the research to address the problem using the perceptions and insight of participants, hence this author's decision to obtain the views of the people directly involved.

This study used a descriptive survey to investigate the perceptions of NQTs and HoDs of the roles of a formal mentor in helping NQTs. The survey used self-administered questionnaires (completed by the participants in their own time) to collect numerical data from NQTs and HoDs in the schools in the sample. These questionnaires were distributed and later collected in person by the researcher. Purposive sampling was used to select eighteen (18) secondary schools, three in each of six districts spread in 3 provinces of Zambia. It was also used to select the $99 \mathrm{HoDs}$ while probability sampling procedures, specifically stratified and simple random sampling, were used to select the 92 newly qualified teachers.

The list of the population for the NQTs was segmented into strata to represent the various sub-groups in the population from which the sample was selected. The stratification included specific characteristics of NQTs to ensure that both female and male, and both diploma and degree holding NQTs were represented in the sample and thereby ensure that the sample reflected the true proportion in the population of the NQTs (Fowler, 2002) 
in Creswell (2009). Using probability sampling, the population of NQTs was stratified based on gender and level of education in order to ensure proportionate representation as the population had more males than females and more degree holders than it had diploma holders. The above consideration took into account the fact that when randomly selecting people from a population, these characteristics may or may not be present in the sample in the same proportions as in the population. Stratification therefore ensured that representation. Simple random sampling was used to select respondents from each stratum.

In this study, quantitative methods of data analysis were used. To facilitate statistical analysis, the Statistical Packages for Social Sciences (SPSS) version 20.0. computer programme for windows, was used to obtain descriptive statistics which include frequencies and percentages. The Pearson's chi-square test was used to determine the relationship among the different phenomena under investigation.

Regarding ethical issues, the study took into account all measures to ensure compliance with all possible and potential ethical issues of concern. Permission was obtained from all relevant authorities in the Ministry of General Education to conduct this study in secondary schools. Before the respondents were asked to participate they were informed about the purpose and focus of the study and oral informed consent was thus obtained from all the respondents. This served as a basis for establishing trust between the researcher and the respondents. The questionnaires were all anonymous. Therefore, participants remained anonymous in order to maintain confidentiality and ensure that no harm comes the way of a participant as a result of the research. The data processing was accordingly guarded from exposure to unauthorised persons. Once data was analysed, the questionnaires and the data were safely stored away until such time that they would be discarded so that they do not fall into the hands of other people [researchers] who might misappropriate them. This study therefore adhered to ethical issues as expected in order to ensure the anonymity, protection and dignity of participants (Creswell, 2009). 


\section{Limitations of the study}

One limitation of the study was the lack of generalisability of the findings because of the non-probability sampling procedures. However, the results are still generalisable to schools with a similar context. In addition, the NQTs cannot be assumed to be objective as they were personally involved in the process that is being investigated. The latter limitation was minimised through triangulation and through obtaining the data from different sub-populations.

\section{Results and discussion}

The findings and discussion has been done in line with the single research question that this paper was attempting to resolve; what are the perceptions of newly qualified teachers and heads of department of the roles of a formal mentor in helping newly qualified teachers in selected secondary schools in Zambia?

\section{General and demographic information}

The profiles of NQTs and HoDs are presented in tables 1 and 2 respectively.

\section{The Perceived Roles of a Formal Mentor in helping newly qualified teachers}

Participants were asked to indicate what they thought the roles of a formal mentor should be in helping newly qualified teachers. The responses are given in table 3.

From the responses they gave, the participants perceived the role of a formal mentor in helping NQTs to be multifaceted as indicated in table 3 . This finding agrees with the findings of other researchers on the topic (Powers, 2012; Lankau and Scandura, 2007; Greiman, 2002; Little, 1990; Bolam, 1984). In particular, the findings of this study agree with (Brading, 1999) who found a similarity with regard to a mentor being expected to help a NQT to be oriented to a new school and develop competence in curriculum subject knowledge.

Table 3 shows that with the exception of one item 'understand labour matters' more HoDs than NQTs had higher ratings of the listed items as perceived roles of a formal mentor in 
helping a newly qualified teacher. Among the HoDs, understand work ethics, improve teaching skills, develop understanding of subject area and prepare lesson plans and schemes of work had the highest ratings.

The researcher wanted to determine if there were any statistically significant differences between the perceptions of the NQTs and the HoDs on the roles of a formal mentor in helping NQTs in secondary schools in Zambia by making comparisons between the two groups. To make this comparison a non-parametric test, the Chi-Square was conducted; the null hypothesis $\left(\mathrm{H}_{0}\right)$ being that there is no significant difference in the perceptions of NQTs and HoDs regarding the roles of a formal mentor in helping newly qualified teachers. The alternative hypothesis $\left(\mathrm{H}_{1}\right)$ was that there is a significant difference in the perceptions of NQTs and HoDs regarding the roles of a formal mentor in helping newly qualified teachers. The statistical tests were run at significance level of 0.05 . Significant levels ( $p$ values) which were less than or equal to 0.05 were significant. Scores of the NQTs and the HoDs were compared on the variables listed in table 3. Table 4 shows a summary of the Chi Square test results obtained for the perceived roles of a formal mentor in helping newly qualified teachers.

As can be seen from table 4 , the results indicate statistical significance on the following items: 'understanding labour matters $\left(x^{2}=5.433 ; p=0.028\right)$, improving teaching skills $\left(x^{2}=12.175 ; p=0.001\right)$, developing understanding of subject area $\left(x^{2}=13.272 ; p=0.001\right)$, managing personal finances $\left(x^{2}=4.982 ; p=0.026\right)$, preparing lesson plans and schemes of work $\left(x^{2}=15.055 ; p=0.001\right)$, and developing interpersonal relationships $\left(x^{2}=7.984\right.$; $p=0.005)$. The null hypothesis that the two groups did not significantly differ is therefore rejected. It was expected that the views of the two groups would be similar in many respects. However, what these results imply is that the views of the NQTs and the HoDs on the roles of the formal mentor in helping NQTs with regard to understanding labour matters, improving teaching skills, developing understanding of subject area, managing personal finances, preparing lesson plans and schemes of work, and developing interpersonal relationships differed significantly. These results imply that NQTs and HoDs expressed significantly different views on what the role of a formal mentor should be in 
helping a newly qualified teacher. This type of disagreement between NQTs and their mentors regarding the roles of a mentor was also reported by (Greiman, 2002) who found that the order of the importance of NQT's needs with regard to professional roles differed from that of mentors. A similar mismatch was also reported by (Brading, 1999) who found differing priorities by NQTs and mentors on areas where mentorship should be focussed. This raises issues of common perceptions of mentor roles.

On the other hand, the results indicate that they were not statistically significant in the following items: in understanding work ethics $\left(x^{2}=2.383 ; p=0.123\right)$, managing personal stress $\left(x^{2}=.694 ; p=0.405\right)$ and protection from job related dangers $\left(x^{2}=.810 ; p=0.368\right)$. The null hypothesis that both groups did not significantly differ is therefore accepted relative to the three items above. These results therefore, were suggesting that both groups held similar perceptions in terms of understanding work ethics, managing personal stress and protection from job related dangers being part of the roles of a formal mentor. This was as expected. This agreement on same aspects of mentor roles is in agreement with the findings of (Greiman, 2002).

Although improving teaching skills, developing understanding of subject area and preparing lesson plans and schemes of work were mentioned by the NQTs, compared to HoDs, NQTs leaned more towards roles of a mentor that reflected non-teaching roles such as induction, orientation and work ethics. The argument is that the focus of NQTs seemed to be on matters related to their own personal well-being such as matters to do with salary, conditions of service and other such related issues as opposed to matters likely to improve their teaching proficiency. In other words, it appeared that their views focused on what they stood to benefit as individuals. These could be classified as 'understand labour matters.'

In contrast to the NQTs, HoDs felt that 'understanding labour matters' should be the least important role of a formal mentor, perceiving matters to do with NQTs competence in teaching-related matters as more important. Heads of department therefore demonstrated a leaning towards instructional needs and abilities of the newly qualified 
teachers. It appears that HoDs were preoccupied with sharpening the skills of NQTs to help them improve their teaching performance relative to the following key professional areas of a teacher's work: improving teaching skills, developing understanding of subject area, and preparing lesson plans and schemes of work. Academic support in these areas would help the teacher develop competence and help a teacher to teach effectively and thereby demonstrate an acceptable level of understanding of the subject content that one is teaching. These findings are consistent with the findings of (Malambo, 2012), who has argued that, teacher preparation such as knowledge of writing schemes, records of work and lesson planning is a professional requirement for teachers in Zambia. In the context of the current study being reported here, the perceived roles of a formal mentor in helping NQTS reported by the participants included improving teaching skills, preparing lesson plans and schemes of work as well as developing understanding of subject area. According to the theory of mentoring by (Kram, 1985), the NQTs focused on psychosocial functions as constituting the roles of a formal mentor while HoDs perceived both psychosocial and career functions sets as constituting the roles of a formal mentor.

The position of the HoDs on this matter therefore reflects dissatisfaction with the performance of NQTs in the stated areas as indicated already, hence the need to provide help to enhance their competence. At the same time however, the HoDs perceived understanding work ethics, protection from job related dangers, managing personal stress, developing interpersonal relationships, and managing personal finances, although not directly related to improvement of efficacy of classroom teaching, as aspects that had the potential to impact on actual classroom teaching and therefore also needed to be addressed by a formal mentor. This agrees with (Little, 1990) who stated that the roles of a mentor included helping NQTs transition from the lecture theatre at university or college to the school classroom.

It is likely that these different understandings of mentoring affected the sorts of support HoDs provided to NQTs and also the attitude of NQTs towards such support/mentorship. The implication is that NQTs will only seek help from veteran teachers in those areas they think they need help. Newly qualified teachers may underestimate the importance of 
certain areas of their practice and consequently not see the need to seek mentoring in those areas. When help is suggested, they may feel that their privacy is intruded.

On the other hand, HoDs will provide mentoring in those areas where they perceive that NQTs needed help. This sets out the more substantive argument that if HoDs do not perceive certain areas as important to NQTs, such as helping them to understand labour matters, they are likely to ignore providing mentoring in such areas, even upon request. These different results in the perceptions of NQTs and HoDs of the roles of formal mentors in helping NQTs, suggest the necessity of concerted efforts to arrive at a common understanding of mentoring. This is important because the needs that a NQT considers important to their successful start to their teaching career will affect the type of help they desire from others.

\section{Comparison by gender of the perceived role of a formal mentor in helping NQTs} In addition to comparing the perceptions of NQTs and HoDs regarding the role of a formal mentor in helping NQTs, the study tested whether there were any associations between gender of NQTs and their perceived roles of a formal mentor using the Chi-Square; the null hypothesis $\left(\mathrm{H}_{0}\right)$ being that there is no significant association between gender and the roles of a formal mentor in helping newly qualified teachers. The alternative hypothesis $\left(\mathrm{H}_{1}\right)$ was that there is significant association between gender and the roles of a formal mentor in helping newly qualified teachers. The statistical tests were conducted at a significance level of 0.05 . Significant levels ( $p$ values) which were less than or equal to 0.05 were significant. Table 5 shows the results of these tests.

Table 5 shows that when the perceived role of a formal mentor was gendered the tests revealed statistically significant associations between managing personal finances and gender $\left(x^{2}=3.928 ; p=.047\right)$. More male participants $(75 \%)$ than female participants $(25 \%)$ agreed that the role of a formal mentor ought to include managing their personal finances. This indicates that there was a relationship between gender and managing personal finances. In this regard therefore, the null hypothesis that there was no significant association between gender and perceived role of a formal mentor in helping NQTs is 
therefore rejected. This agrees with the findings of McKeen and Bujaki (2007) who studied cross-gender and same gender relationships in mentoring and found differences in the focus of mentors during mentoring relationships based on gender. The relationship between gender and managing personal finances in the Zambian context could be explained by the fact that females were trained to manage the affairs of a home that included budgeting, at an early or tender age compared to their male counterparts. This gave them a perceived sense of maturity and responsibility in handling matters of the home which included finances.

However, gender was not associated with the perceived role of a formal mentor in terms of understanding labour matters, understanding work ethics, managing personal stress, improving teaching skills, developing understanding of subject area, preparing lesson plans and schemes of work, developing interpersonal relationships, and protection from job related dangers, all tested at ( $p$ value $>0.05)$. These results imply that male and female NQTs expressed similar views regarding the perceived role of a formal mentor in helping NQTs on all but one item; managing personal finances. The null hypothesis that there was no significant association between gender and the perceived role of a formal mentor in helping NQTs is therefore accepted.

\section{Comparison by level of education of the perceived role of a formal mentor in helping NQTs}

Similar analyses were conducted to determine further whether there were any associations between educational level of NQTs and perceived roles of a formal mentor in helping newly qualified teachers. Chi Square tests were conducted; the null hypothesis $\left(\mathrm{H}_{0}\right)$ being that there is no significant association between the educational level of NQTs and the perceived roles of a formal mentor in helping NQTs. The alternative hypothesis $\left(\mathrm{H}_{1}\right)$ was that there is significant association between the educational level of NQTs and the perceived roles of a formal mentor in helping NQTs. The statistical tests were run at significance level of 0.05 . Significant levels ( $p$ values) which were less than or equal to 0.05 were significant. The results are shown in table 6. 
Table 6 shows that there was no significant association between educational level and perceived roles of a formal mentor $(p>.05)$. These results imply that in spite of the differences in the duration of training, each group of NQTs expressed similar views about the roles of a formal mentor in helping newly qualified teachers. Therefore, the null hypothesis that there is no significant association between the educational level of NQTs and the perceived roles of a formal mentor in helping NQTs, is accepted. This disagrees with the views of Greiman (2002) who established a clear difference in perception of the roles of a mentor based on level of qualification.

\section{Conclusion and Recommendations}

It is clear from the findings of the study that both NQTs and HoDs appreciated the role of mentors in the professional development of newly qualified teachers. However, although there was some agreement on some aspects of the roles of a mentor, the findings indicate that NQTs and HoDs reported a great disparity in their understanding of what should constitute the mentorship provided by veteran teachers. In view of this, it is not only important but necessary that whatever mentorship programme is to be developed; and whatever the nature of the collaboration between the mentor and mentee should respond to the identified needs of the NQT within a given context, and not to a general mentorship programme. It is clear from the foregoing that NQTs must be comprehensively supported if the potential in them is to be fully tapped and developed.

On the basis of these findings, the following recommendations are made:

- The differences in understanding the roles of mentoring by NQTs and HoDs reflects the need by the Ministry of General Education for a policy on mentorship so as to provide institutionalised guidance and create a synchronised understanding and practice of mentoring in schools that responds to the needs of NQTs.

- Schools should create structures that provide opportunities for experienced teachers to work with NQTs for the benefit of the NQTs, learners and the school as an organisation. 
- The Ministry of General Education should conduct a needs assessment anchored on a bottom-up approach in order to avoid prescribing to stakeholders programmes that do not reflect the needs of the newly qualified teachers.

- Teacher educators should develop interest in the challenges faced by NQTs in the first few years of their practice in order to forestall some of these challenges during initial teacher training.

\section{Disclosure statement}

No potential conflict of interest was reported by the authors.

\section{Notes on contributor}

Madalitso K. Banja is Lecturer with the Department of Educational Psychology,

Sociology and Special Education, University of Zambia, Zambia

\section{References}

Bartell, C.A. 2005. Cultivating High Quality Teaching Through Induction and Mentoring. California: Corwin Press.

Bolam, R. 1984. Induction of beginning teachers. In: Husen, T. \& Postlewaite, N. (eds.). International Encyclopedia of Educational Research. Oxford: Pergamon Press.

Brading, M. 1999. The Induction of newly qualified teachers: perceptions of the professional development of NQTs as described by new teachers, their mentors and head teachers. Paper presented at the British Education Research Association Annual Conference, University of Sussex at Brighton, September 2-5 ${ }^{\text {th }}$. Accessed 20/06/2017 http://www.leeds.ac.uk/educol/documents/00001227/htm

Clutterbuck, D. 2007. An International Perspective on mentoring. In: B.R. Ragins and K.E. Kram (eds.). The Handbook of Mentoring at Work: Theory, Research and Practice. Thousand Oaks: SAGE Publishing.

Cochran-Smith, M. 2005. The new teacher education: For better or for worse? Educational Researcher, 34: 3-17.

Creswell, J.W. 2009. Research Design; Qualitative, Quantitative, and Mixed Methods Approaches. London: SAGE Publishing. 
Dougherty, T.W and Dreher, G.F. 2007. Mentoring and Career Outcomes; Conceptual and Methodological Issues in an Emerging Literature. In: B.R. Ragins and K.E. Kram (eds.). The Handbook of Mentoring at work: Theory, Research and Practice. Thousand Oaks: Page Publications

Feiman-Nemser, S. 2003. What new teachers need to learn. Educational Leadership, 60: 25.

Fowler, E.J. 2002. Survey Research Methods. (3 $3^{\text {rd }}$ edition). Thousand Oaks, CA: Sage Galvez-Hjornevik, C. 1985. Teacher Mentors: A Review of the Literature. Journal of Teacher Education, 37: 6-11

Greiman, B.C et al. 2007. Beginning teachers' perceptions of In-School and In-Profession Mentoring Relationships. Career and Technical Education Research, 32: 45-67

Greiman, B. C. 2002. 'Providing professional and psychological assistance for beginning agriculture teachers: The perceptions of formal mentors and novice teachers'. PhD Thesis. Missouri: University of Missouri-Columbia.

Gwaa-uugwanga P. 2015. 'Teacher educators' perceptions about possibilities and challenges of the merger between Namibian Higher Education institutions for improving teacher education'. PhD Thesis. Cape Town: University of the Western Cape

Huling-Austin, L. 1990. Teacher induction programs and internships. In: W. R. Houston, M. Haberman, \& J. Sikula (eds.). Handbook of research on teacher education. Reston, VA: Association of Teacher Education.

Ismail- M. \& Arokiasamy, L. 2007. Exploring mentoring as a tool for career advancement of academics in private higher education institutions in Malaysia. The Journal of International Social Research, 1: 136-149

Jyoti, J. \& Sharma, P. 2015. Impact of Mentoring Functions on Career Development: Moderating Role of Mentoring Culture and Mentoring Structure. Global Business Review, 16: 700-718

Kram, K. E. 1985. Mentoring at work. Boston: Scott, Foresman and Company.

Lankau, J.M. and Scandura, A.T. 2007. Mentoring as a Forum for Personal Learning in Organisations. In: Ragins, B.R. \& Kram, K.E. (eds.). The Handbook of Mentoring at Work: Theory, Research and Practice. Thousand Oaks: SAGE Publications. 
Lennox, S., Skinner, J., \& Foureur, M. 2008. Mentorship, preceptorship and clinical supervision: Three key processes for supporting midwives. New Zealand College of Midwives Journal, 39: 7-12

Little, J.W. 1990. The Mentor phenomenon and the social organisation of teaching. In: C. B. Cazden (ed.). Review of research in education Vol.16, 297-351. Washington DC: American Educational Research Association.

Lortie, D. 1975. Schoolteacher: A sociological study. Chicago: University of Chicago Press.

Malambo, B. 2012. 'Factors affecting pupil performance in Grant-aided and non-Grant aided Secondary Schools: A case of selected secondary schools in the Western Province of Zambia'. MEd dissertation. Lusaka: University of Zambia

Malasha, E.C. 2009. 'New teacher Induction programmes and practices in selected high schools of Lusaka province'. MEd dissertation. Lusaka: University of Zambia.

McCollum, I.P. 2014. 'Beginning Teachers' Perceptions of a Teacher Mentoring Programme. Doctoral Thesis. Walden: Walden University.

McKeen, C. \& Buyaki, M. 2007. Gender and Mentoring: Issues, Effects, and Opportunities. In: B.R. Ragins and K.E. Kram (eds.). The Handbook of Mentoring at work: Theory, Research and Practice. Thousand Oaks: Sage Publications.

Morton-Cooper, A., \& Palmer, A. 2000. Mentoring, Preceptorship and Clinical Supervision: A guide to professional support roles in clinical practice (2nd ed.). Oxford: Blackwell Science Ltd.

Odell, S. J. 1990. Mentor Teacher Programs. Washington, DC: National Education Association.

Powell, M. A. 1997. Academic tutoring and mentoring: A Literature review. California Research Bureau Sacramento, CA 95814 CRB-97-011 (916) 653-784

Powers, K. 2012. 'New Teachers' perceptions on their preparation: A follow-up study'. Graduate Theses and Dissertations. Paper 12438.

Ragins, B.E. and Kram, K.E. 2007. The roots and meaning of mentoring. In: B.R.

Ragins and K.E. Kram (eds.). The Handbook of Mentoring at work: Theory, Research and Practice. Thousand Oaks: Sage Publications.

Renwick, L. 2007. Keeping new teachers happy. District Administration, 43: 26. 
Richter, D, Kunter, M., Ludtke, O., Klusmann, U., Anders, Y., \& Baumert, J. 2013. How different mentoring approaches affect beginning teachers' development in the first years of practice. Teaching and Teacher Education, 36: 166-177.

Simon, S. and Wardlow, G. 1989.

Surtees, R. 2008. Inductions of labour': on becoming an experienced midwifery practitioner in Aotearoa/New Zealand. Nursing Inquiry, 15: 11-20.

Turner, M. and Bash, L. 1999. Sharing Expertise in Teacher Education. London. Cassell.

Verasai, A. 2016. Role of Mentoring in Career Development. Las Vegas. The HR Digest. https://www.thehrdigest.com/role-of-mentoring-in-career-development/

Wayne, A., Youngs, P., \& Fleischman, S. 2005. Improving teacher induction. Educational Leadership, 62: 76-78.

Wildman, T. M., Niles, J., Maglario, S. \& McLaughlin, R. 1987. Teaching and Learning to teach: the two roles of the elementary school teacher. The Elementary School Journal, 89: 4.

Wong, H. 2004. Induction programs that keep new teachers teaching and improving. NASSP Bulletin, 88: 41-58. 